\title{
Promoting a culture of health and safety at work: safety - a permanent priority
}

\author{
R. Chaib ${ }^{1}$, I. Verzea ${ }^{2}$, M. Benidir ${ }^{1} \&$ M. Taleb ${ }^{3}$ \\ ${ }^{1}$ Laboratory of Transport Engineering and Environnement, \\ Mentouri University, Constantine, Algeria \\ ${ }^{2}$ Technical University Gh. Asachi Iasi, Romania \\ ${ }^{3}$ Sheikh Larbi Tebessi University, Tebessa, Algeria
}

\begin{abstract}
The human consequences of occupational accidents in Algeria are multiples of their action on the profitability and the added value, knowing that the company is the employee's home and the damage of each may affect the whole. Moreover, understanding and applying concepts of risk management in their Anglo-Saxon sense is completely absent in our companies. Preventive measures are still insufficient, especially for the protection of workers who are often left on their own. This results in an uneven maturity of companies, different strategies considered and dissimilar organizational choices. Of the more than 50,000 accidents/year that have been recorded in Algerian companies, between 750 and 800 of those accidents have caused deaths. The number of days lost that are automatically compensated is $1410^{5}$. These costs are exorbitant for the whole of society and even more so for the companies themselves (the continuing rise of absenteeism, disruption of ongoing work and lost production, etc...). Conscious of the importance of industrial safety control for the future of our industrial heritage, we covet raising employees' and employers' awareness on the importance of all issues raised by technological risks within companies. Everything has to be done in order to avoid an accident which breaks or handicaps a human life; the objective of this paper. Instantly, everything has to be done to ensure the means to provide occupational health and make the industrial action daily to ensure the safety of its personnel in different companies or even in each workplace. Thus, a permanent anticipation of work accidents and occupational diseases can therefore be reached and to develop a permanent and sustainable culture of prevention in companies. So we hope that prevention is on
\end{abstract}


the agenda of each employer, each worker, all employers' associations, trade unions and professionals. Safety and health at work should be seen as a tool for productivity and an economic asset. Only in this way, individually and collectively, risks can be controlled and sources of danger can be eliminated for the health, safety and physical integrity of workers, while relying on the general principles of prevention: the health in the company is the health of the company. Keywords: management, cement plant, improvement, industrial hygiene and safety, risks and preventive measures.

\section{Introduction}

In principle, compliance with legislation, standards and recommendations in effect, health and safety of work should ensure conditions of adequacy. Unfortunately, today in practice, the situation is considerably more complex. On the one hand, technological progress and intense competitive pressures lead to rapid changes in conditions and work processes and organization. On the other hand, the cost of accidents and occupational diseases is exorbitant for the whole of society and even more so for the company itself (the continuing rise of absenteeism, disruption of ongoing work and lost production, etc..) [1]. Henceforth, it is very difficult to guarantee a match between the actual risk involved and the preventive measures taken. Besides, legislation is necessary but not sufficient to cope with these changes and stay abreast of new risks. Furthermore, it should be noted that the usual preventive measures are still insufficient to address this issue and that the majority of workers are often left to their own [2]. Despite its importance, safety remains an unknown subject to many managers. Put forward, safety remains for the hygiene, safety and environment (HSE) responsible a fight at all times in many companies. This results in uneven maturity of companies, different strategies considered and dissimilar organizational choices. Therefore, assess the potential risks in the workplace in any tasks before occurrence of malfunctions, accidents or occupational diseases, is a prerequisite for building an action plan of relevant prevention [3]. The implementation of a safety management and occupational health system provides an effective means to fulfil that obligation [4]. Henceforth, the company's role is to assess measures that will facilitate individual awareness and enable all employees to take charge of their own physical and mental health [5].

\section{General principles of prevention}

Prevention of occupational hazards is the set of early actions aimed at controlling the risk of accidents and/or diseases and to improve working conditions by technical, organizational and human solutions. However, the problem of occupational health that currently exists and tends to spread will not be curbed as long as the factors that are at its origin will not be determined, recognized and corrected $[6,7]$. Good organization can save time, avoid generating incidents of 
accidents, to reconcile the quality and safety [8]. The general prevention principles can be presented as follows [9]:

\subsection{Assessing risks}

- Manufacturing processes;

- Materials, substances or products used;

- Work equipment;

- Development of the workplace;

- Workstations.

\subsection{Incorporate the safety upstream}

- Building design;

- Definition of processes;

- Selection of work equipment.

\subsection{Organize work}

- Limit the employees number at risk;

- Establish procedures and work instructions.

\subsection{Limit the risks to individuals}

- Implement the means of collective protection;

- Arrange positions or intervene on work equipment;

- Provide appropriate IPE to residual risks.

\subsection{Inform on the risks and protection}

- Inform on the nature of risk;

- Inform on the prevention measures de implemented in the company;

- Inform on control effectiveness of protection means.

\subsection{Training on safety}

- Provide training and adapt to the employees needs;

- Renew the training periodically and with each change of work processes and procedures;

- Training in the use and maintenance of individual protective equipment (IPE) available:

- Raise awareness, inform, educate and remind whenever necessary.

\section{Some recommendations to reduce the risk in a company}

\section{$[8,10,11]$}

\subsection{Risks associated with work equipment}

- Use machines and tools in compliance with regulatory requirements;

- Integrate the safety aspect when buying; 
- Use work equipment as prescribed by the supplier;

- Facilitate the operations of assembly and disassembly tools;

- Install a protective cover to sharp tools parts (envelop, equipped site) when they are no longer in use;

- Record the work equipment before any repair or maintenance;

- Establish procedures incorporating safety;

- Train staff;

- Ensure the wearing of required personal protective equipment (goggles, gloves, etc.).

\subsection{Chemical risks}

- Replace a hazardous material with a less hazardous;

- Limit the products handling;

- Check the labelling of supplied and properly label the split units:

- Supply products in the most convenient packaging for use;

- Capture products delivered by the source (cab, hood ...) and ventilate the area;

- Inform staff of precautions for use of products;

- Eliminate leakage products;

- To wear appropriate personal protective equipment (gloves, goggles, respirators, etc.);

- Establish safe operating procedures;

- Consider the processing, storage and waste disposal.

\subsection{Risks associated with electrical installations}

- Recording facilities before any intervention;

- To carry out electrical installations by qualified personnel with appropriate equipment:

- Periodically check the electrical installations;

- Inform staff of electrical hazards; marking of danger areas, access restrictions, emergency instructions;

- Train staff and to issue securities in accordance with the enabling tasks to be performed;

- Ensure the closure of cabinets, cupboard and electrical rooms;

\subsection{Physical risks}

- Remove the noise sources, limit its intensity;

- Put the facilities and noise equipment in separate and isolated areas;

- Install protections; rollover, cabinet, cab, acoustic treatment of the local walls;

- Limit the noise exposure time to staff;

- To wear personal protective equipment: ear plugs, ear muffs, etc.;

- Ensure that lighting is adequate and appropriate for the type of work to be done; 
- Focus on natural light wherever possible;

- Set up work for light and suitable positions;

- Adapting workplaces to the characteristics and people abilities;

- Eliminate vibrations emitted by certain plant or machinery;

- Avoid workplaces at low or high temperature;

- Ensure adequate natural or forced ventilation in areas or confined workplaces;

- Protect the devices emitting ionizing radiation.

\subsection{Crafts}

- Organize work stations to eliminate or reduce the handling;

- Limit the unit weight of handled loads;

- Use of handling equipment: pallet, trolley, etc.;

- Use proper upgrade means: lift table dock, lift gate, etc.;

- Equip loads of handles means: handles, suckers, trays, etc.;

- Train staff to adopt appropriate gestures and postures;

- Limit the tasks duration that require repetition;

- To wear personal protective equipment: gloves, shoes, etc.

\subsection{Mechanical handling, moving}

- Ways and means for handling and accessories comply with regulations;

- Only use suitable means to the task to be done, under the conditions and the requirements of the manufacturer;

- Regularly check their condition and regulatory checks;

- Limit their use to only trained and certified and found able;

- To ensure visibility and in good soil;

- Organize the flow of people and vehicles;

- Report and maintain roads and manoeuvring areas.

\subsection{Fire risk - explosion}

- Organize storage taking into account the products compatibility;

- Replace hazardous products with a less hazardous;

- Remove the sources proximity: flame, cigarette, welding equipment, etc.;

- Install protections: isolated rooms, wall and fire door;

- Install appropriate extinguishing means: fire extinguishers, fire blankets, etc.;

- Installing detection means and alarm;

- Establish intervention plans (fire instructions, exercise with fire brigade...) and evacuation (emergency

- exit, signs, etc.); 


\subsection{Workplaces}

\subsubsection{Movements on the ground floor}

- Organise the persons movements within the establishment precincts;

- Remove hazardous areas by placing flooring; non-slipping, removing ground inequalities (small step, stage, nick...) and enlargement of the passages;

- Maintain soil: periodic cleaning and immediate in case of product application, repair of detective parts, etc.;

- Maintain wide passages, released, reported and enlighten. Outlaw storage.

\subsubsection{Risks of falls from height}

- Remove areas with level difference and height access;

- Establish protections; hand rails, guard rail, fence lock, cargo net, etc.;

- Use the moving platforms to the height work time;

- Train staff to ensure the correct use of mobile devices and a regular check of their strength;

- To carry personal protection (harnesses, stop falling, etc.);

- Avoid the use of ladders as workstations.

\subsection{Road traffic}

- Anticipate and travel arrangements: schedule, duration, recommended route, specific plan for access to the destination;

- Maintain vehicles regularly;

- Repair immediately in case of failure;

- Organize working time;

- Train staff on how to drive safely.

\section{Individual behaviour}

Beyond the technical and organizational measures, a responsible company may also seek to promote among its employees a healthier lifestyle, to empower health, with particular emphasis on prevention of serious and frequent illnesses (cardiovascular, cancer, diabetes) and the benefits of a healthy lifestyle [5]. The employees' individual hygiene staff participates in the occupational health [12, 11]. Working conditions have an impact on health. Conversely, individual behaviour in terms of wearing personal protective equipment, hand washing, respiratory hygiene, hydration, nutrition, sleep or physical activity affect health and safety at work and must be adapted to the professional activity. Personal hygiene is part of preventive measures against occupational diseases [13].

The hands are a soiled vector of contamination, for himself or his environment (both private and professional), sometimes through useful objects (door handles, tools, pencils, telephone...). The work clothes can also be contaminated: while they represent a risk for the employee and his entourage. 
Occupational health necessarily requires regular cleaning of the hands, clothing used during labour and personal protective equipment.

Henceforth, bacteria, viruses, chemical and biological stains, dust, etc, can carry a large number of chemical or biological substances potentially hazardous to health by their hands and work clothes. Some hygiene at work, aided and supported by an appropriate organization, can prevent some of the risks associated with these professional nuisances.

The occupational health is based mainly on [12]:

- Individual behaviour (wearing appropriate protective equipment, hand washing, nutrition, hydration and sleep adapted to the work constraints, physical activity);

- Suitable workplace (installations sanitation, ventilation and clean air, rest room and catering...);

- The maintenance and regular cleaning of the premises and work equipment.

Issues relating to personal hygiene are difficult to address because the personal employees sphere. Companies can, through occupational doctors and responsible of health and safety, give their employees some advice (awareness, display, information, etc.).

Therefore, the employer must implement measures to reduce occupational hazards, to inform employees to focus on behaviour and to available appropriate equipment. Sanitation facilities have sinks, toilets, changing rooms and if necessary, showers in sufficient numbers and in good state.

Organizational measures must be based on sound analysis of working conditions: to have points close to washing dirty jobs, ensure regular cleaning of these facilities, ensuring the comfort and privacy of users, etc.

Finally, it should be noted that the repeated lack of sleep can have adverse consequences (hypertension, gastrointestinal disorders, viral infections, depression, headache, loss of motivation, learning disabilities, school dropouts, professional concerns), drowsy driving, the leading cause of motorways accidents. Sleep deserves its rightful place and it is important to sleep well and enough to meet the challenges of each new day [14]. Thus, the quality and duration of sleep or rest have a significant impact on work. Disturbed sleep can cause drowsiness, loss of alertness and an increased accidents risk.

It is quite clear that workers in good health improve company productivity, profits and national economy by reducing the number of accidents and diseases, and therefore, the requests for interventions and insurance compensation [15].

\section{Conclusion}

The contemporary objectives of industrials trend is zero risk or zero accidents and zero incidents, as industrial accidents and professional diseases have a huge impact on the workers' health and considerable economic and social consequences. As a result, safety and accident prevention are an absolute necessity for the entity survival. It is a company priority, or any industrial activity. Henceforth, experience has shown that prevention prévention reduces 
the risk, accidents can be avoided [16] and that success is related to the actions coherence. Therefore, the company safety level must further be improved, identify the causes of accidents and injuries and make the necessary priority measures preventive and corrective. Priorities should be identified to guide the best choice of the company.

To change radically the company in this area, it must incorporate the banner "prevention is everybody's business" and put it into practice, involving all staff in the management approach to prevention. Besides, to improve health and safety of employees, every company must engage in continuous improvement [2]. Finally, the best prevention practices have been recommended [17].

1. Integrate the health and safety management in all company functions;

2. Harmonize health and safety policy with other company policies;

3. Developing the company autonomy in terms of prevention;

4. Encourage a multidisciplinary approach;

5. Make the identification and evaluation of a priori risk of a major health policy and safety;

6. Integrate prevention into the design of premises, equipment, jobs and working methods;

7. Analyzing accidents and occupational diseases caused earlier;

8. Improve risk management policy and develop the company base values.

Finally, it should be remembered that, "the tiles that protect from rain were all put in good weather".

\section{References}

[1] Anthony Colombani-Poggi, Les pratiques de gestion prévisionnelle dans les centres de gestion; Éléments pour un premier bilan, CIG grande couronne, service Analyse et prospective sociale, 2005.

[2] Chaib Rachid and Ion Verzea, Strategy of a continuous improvement steps in safety: case of shovel and cranes factory, Management of technological changes "MTC 2009", September 3TH-5TH Alexandroupolis, Greece.

[3] Ghania Chaib, Rachid Chaib et Ion Verzea, From the risks evaluation to the health and safety preservation at work, Environment Engineering and Management Journal, Vol.8, N³, Pp483-486, May/June 2009.

[4] BIT, Principes directeurs concernant les systèmes de gestion de la sécurité et de la santé au travail, ILO-OSH, ISBN 92-2-211634-8, Bureau International du travail Genève 2002.

[5] G. Künzi, J.-C. Rielle, Manager la santé dans l'entreprise, PME et développement durable, Editions Carrefour Prévention, Genève, 1998.

[6] Estelle Morin, Sens du travail, santé mentale et engagement organisationnel; santé psychologique; Etudes et recherches, Rapport R-543, ISSN; 0820-8395, 2008.

[7] Centre Patronal de santé et sécurité du travail au Québec; Les outils du comité de santé-sécurité; guide pratique, ISBN 2-922991-35-0. Mise à jour aout 2005, Québec, Canada. 
[8] M. Bossard et al. Les activités de mise en propreté et services associés, prévention des risques, ED 963, INRS 2005.

[9] Dossier travail et sécurité, Protection Individuelle, INRS, mise à jour 09/01/2006.

[10] Service de santé au travail; L'évaluation des risques professionnels; le document unique, ASMI, Annecy, novembre 2002.

[11] C. Soudry, Mise à disposition et port des équipements de protection individuelle; Droit en pratique, Travail et sécurité, №636, janvier 2004.

[12] Dossier; Hygiène au travail; pour aller plus loin, INRS, ED583, mise à jour 02/07/2009.

[13] Dossier travail et sécurité $\mathrm{N}^{\circ} 616$, Hygiène corporelle sur les lieux de travail; l'eau, source de propreté, INRS, mars 2002.

[14] Damien Léger, Alain Nicolas, Joël Paquereau, Sylvie Royant-Parola et Véronique Viot-Blanc; Bien dormir, mieux vivre, le sommeil c'est la santé, Réf; 421-09648-B, 2009.

[15] Dr Sameera Al-Tuwaijri, Directrice du Département Safework du BIT; Une journée pour la santé et la sécurité au travail, le 29/04/08.

[16] Bertrand. Collomb, Président directeur Général, Politique santé et sécurité Groupe, Ensemble, faire de Lafarge l'entreprise la plus sure de son secteur, Lafarge, Septembre 2002.

[17] Politique de maîtrise des risques professionnels; Valeurs essentielles et bonnes pratiques de prévention; VALEURS ESSENTIELLES; Institution Prévention (CNAMTS, INRS, CRAM, CGSS, EUROGIP) CNICC du 29 mai 2001. 